\title{
"Cutis tricolor": congenital hyper- and hypopigmented macules associated with a sporadic multisystem birth defect: an unusual example of twin spotting?
}

Department of
Dermatology,
University of Marburg,
35033 Marburg,
Germany
R Happle

Department of Clinical Genetics, University of Ulm, 89073 Ulm, Germany

G Barbi

I Kennerknecht

Department of Paediatrics, Social Paediatrics Unit, University of Ulm, 89077 Ulm, Germany D Eckert

Correspondence to: Dr Happle.

Received 9 August 1996 Revised version accepted for publication 14 February 1997

\author{
R Happle, G Barbi, D Eckert, I Kennerknecht
}

\begin{abstract}
An uncommon coexistence of circumscribed hyperpigmentation and hypopigmentation, in close proximity to each other, is described in a 17 year old patient with various other congenital defects, such as dysmorphic facial appearance, severe kyphoscoliosis, delayed motor development, epileptic seizures, and mental retardation. We suggest the combination of hyper- and hypopigmented cutaneous lesions is an example of allelic twin spotting. Because the skin of this patient showed three different degrees of pigmentation, the term "cutis tricolor" is proposed.

(F Med Genet 1997;34:676-678)
\end{abstract}

Keywords: pigmentary naevi; mosaicism; loss of heterozygosity; twin spotting

Congenital pigmentary disturbances arranged in a linear or otherwise segmental form are often associated with asymmetrical extracutaneous anomalies and usually reflect genetic mosaicism. ${ }^{12}$ In accordance with this concept, cytogenetic examination has shown various states of mosaicism in patients affected with so-called hypomelanosis of Ito, a cutaneous pattern that almost exclusively occurs sporadically..$^{3-6}$ We report here an unusual case with multisystem birth defects showing circumscribed areas of hyperpigmentation and hypopigmentation, and we suggest a common origin of the two skin lesions by the mechanism of allelic twin spotting.

\section{Case report}

A 17 year old man had severe mental retardation, markedly delayed motor development, and multiple dysmorphic features. His parents were healthy and non-consanguineous. $\mathrm{He}$ was born at term after an uneventful pregnancy. A first pregnancy had been aborted in the third month of gestation because of persistent bleeding; no further information regarding this event was available. His birth weight was $2950 \mathrm{~g}$ and length was $50 \mathrm{~cm}$. He sat at the age of 9 months and walked at 2 years. From the age of 8 years he has occasionally suffered from generalised cerebral convulsions. $X$ rays of the skull performed at this age showed marked digital impressions but a CT scan showed normal findings. At the age of 10 years, an electro- myogram gave normal results. Ophthalmological examination showed convergent strabismus of the right eye as well as bilateral hyperopia and astigmatism, but otherwise normal structures. Testing for $\alpha$-fetoprotein as well as analysis of amino acids and long chain fatty acids gave normal results.

On examination at the age of 17 years his height was $145 \mathrm{~cm}$ (18 cm below the 3rd centile), his weight was $42.4 \mathrm{~kg}$ ( $5 \mathrm{~kg}$ below the $3 \mathrm{rd}$ centile), and head circumference $52 \mathrm{~cm}(1.5$ $\mathrm{cm}$ below the 3 rd centile). He had bushy eyebrows, deep set and backward rotated ears, broad nostrils, and prognathism (figs 1 and 2). A pronounced kyphoscoliosis resulting in chest deformity was present (fig 2). His hearing appeared to be normal and his muscle tone and joint mobility were also normal. An EEG showed polyspike-wave complexes. A ventricular septal defect had been closed surgically at the age of 9 years. On ultrasonographic examination, thoracic and abdominal organs were otherwise normal. The testes were not palpable and a CT scan failed to show them within the abdomen. However, an HCG test indicated the presence of functionally active testicular tissue.

On examination of the skin, a peculiar pigmentary disturbance was noted. On the right side of his body multiple segmented areas of café au lait hyperpigmentation involved the mandibular area and the arm. In addition, ipsilateral, well demarcated areas of hypopigmentation were present on the neck and the shoulder, in close proximity to the hyperpigmented lesions (fig 3).

Punch biopsies were obtained from both hyper- and hypopigmented skin areas and fibroblast cultures were performed. Cytogenetic analysis of skin fibroblasts and peripheral blood lymphocytes ( 50 metaphases each; GTG banding technique, approximately 550 band stage) showed a normal 46,XY karyotype without any anomaly indicating mosaicism.

\section{Discussion}

In this sporadic case with multisystem birth defects, the associated pigmentary skin lesions suggest genomic mosaicism. Scoliosis and asymmetry of the trunk are frequently observed in cases of chromosomal mosaicism, especially in patients with so-called hypomelanosis of Ito. ${ }^{1378}$ The fact that in the present case cytogenetic analysis gave normal results 


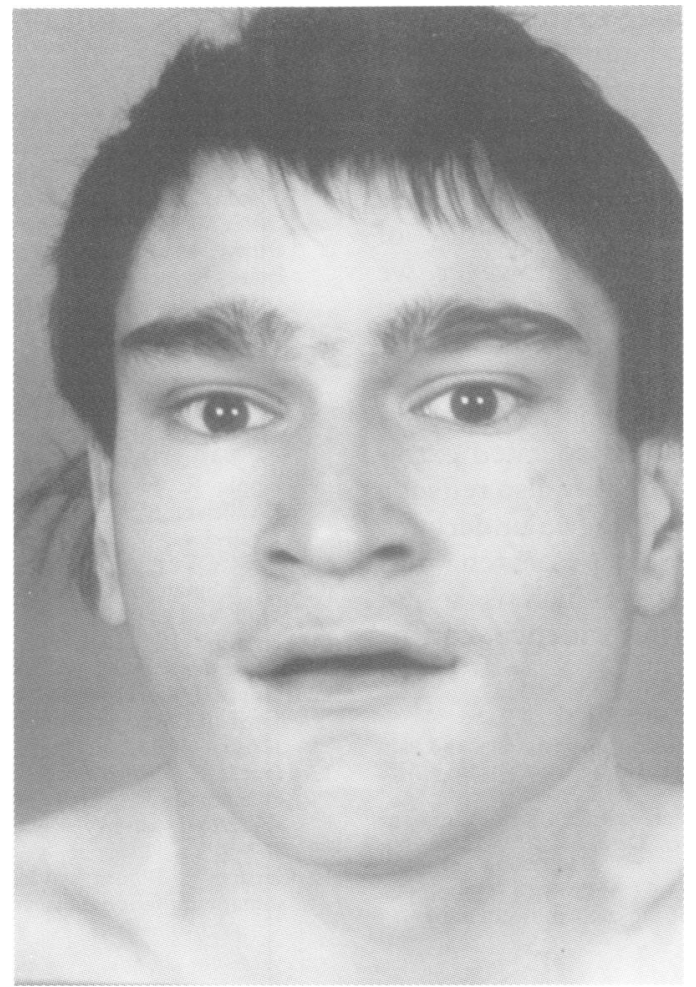

Figure 1 Dysmorphic facial appearance with bushy eyebrows and broad nostrils.

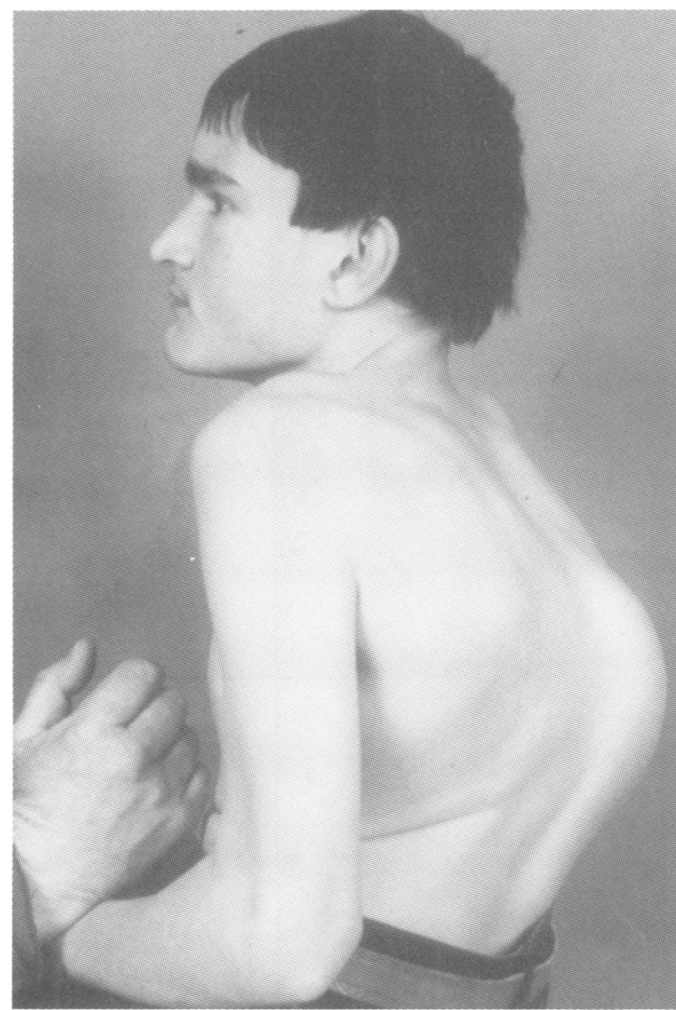

Figure 2 Prognathism, deep set and backward rotated ears, and chest deformity resulting from kyphoscoliosis.

does not exclude a mosaic state at the molecular level.

It could be argued that this syndromic association should be categorised as an example of hypomelanosis of Ito. ${ }^{57}$ However, it is now clear that "hypomelanosis of Ito" does not constitute a distinct entity but represents a cutaneous sign of numerous different states of mosaicism. ${ }^{26}$ For this reason the term

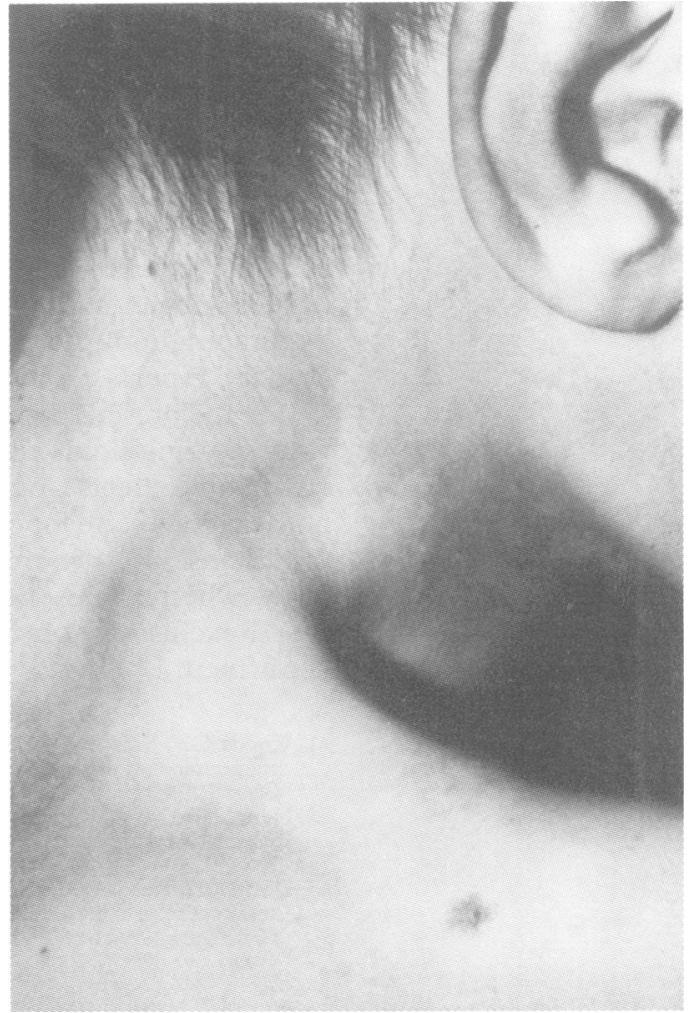

Figure 3"Cutis tricolor": hyperpigmented spots close to hypopigmented macules involving the neck and the shoulder on the right side. Normally pigmented skin is present on the left half of the lowermost part of the photograph.

hypomelanosis of Ito no longer has a specific meaning other than "pigmentary mosaicism". Some authors have proposed that the name hypomelanosis of Ito should be reserved for pigmentary disturbances following the lines of Blaschko, ${ }^{1}$ but other arrangements, such as a chequerboard pattern or phylloid pattern, may also be observed. ${ }^{9}$ In the present case the pattern of the cutaneous lesions was dissimilar to Blaschko's lines but could not be classified further.

An unusual combination of hyper- and hypopigmented cutaneous lesions was noted in this patient. Because his skin showed three different degrees of pigmentation, we propose the new term "cutis tricolor".

This phenomenon may be explained by the genetic mechanism of twin spotting. ${ }^{2}{ }^{10}{ }^{11} \mathrm{At}$ one of the various gene loci controlling skin pigmentation, the embryo would carry two alleles responsible for either increased or decreased melanin production. The two alleles would balance each other, resulting in an intermediate skin pigmentation. During early embryogenesis, a somatic recombination event would give rise to two daughter cells being homozygous for either allele. These would be the stem cells of pigmentary twin spots.

A similar mechanism has been proposed to explain several other human phenotypes, such as vascular twin naevi defined by coexistence of naevus telangiectaticus and naevus anaemicus ${ }^{12}$; phacomatosis pigmentovascularis, a phenotype characterised by the coexistence of a telangiectatic naevus and a widespread pigmentary naevus ${ }^{2} ;$ and phacomatosis pigmentokeratotica, a disorder 
representing a melanocytic-epidermal twin naevus syndrome. ${ }^{13} \mathrm{~A}$ relationship between somatic recombination and twin spotting in the form of café au lait macules and depigmented spots would be particularly conceivable in Bloom syndrome, in which direct evidence exists for an increase in the frequency of somatic recombination. ${ }^{14}$ So far, however, we have not been able to find conclusive clinical documentation of this phenomenon in the availabe reports on Bloom syndrome.

If in the present case the proposed concept of twin spotting holds true, the associated extracutaneous defects would probably also reflect a homozygous state for one of the two underlying mutations. Future molecular research may show whether this concept, which is so far based exclusively on clinical evidence, can be confirmed.

1 Woods CG, Bankier A, Curry J, et al. Asymmetry and skin pigmentary anomalies in chromosome mosaicism. $f \mathrm{Med}$ Genet 1994;31:694-701.

2 Happle R. Mosaicism in human skin: understanding the patterns and mechanisms. Arch Dermatol 1993;129:1460 70.

3 Donnai D, Read AP, McKeown C, Andrews T. Hypomelanosis of Ito: a manifestation of mosaicism or chimerism. $\mathscr{F}$ Med Genet 1988;12:809-18.
4 Thomas IT, Frias JL, Cantú ES, Lafer CZ, Flannery DB, Graham JG Jr. Association of pigmentary anomalies with chromosomal and genetic mosaicism and chimerism. $A m \mathcal{F}$ Hum Genet 1989;45:193-205.

5 Sybert VP, Pagon RA, Donlan M, Bradley CM. Pigmentary abnormalities and mosaicism for chromosomal aberration: association with clinical features similar to hypomelanosis of Ito. $\mathcal{F}$ Pediatr 1990;116:581-6.

6 Küster W, Ehrig T, Happle R. "Hypomelanosis of Ito": no entity, but a cutaneous sign of mosaicism. In: Nordlund J, Boissy R, Hearing V, King R, Ortonne JP, eds. The pigmentary system and its disorders. New York: Oxford University tary system and

7 Takematsu H, Sato S, Igarashi M, Seiji M. Incontinentia pigmenti achromians (Ito). Arch Dermatol 1983;119:391-5.

8 Ohashi H, Tsukahara M, Murano I, et al. Pigmentary dysplasias and chromosomal mosaicism: report of 9 cases. Am f Med Genet 1992;43:716-21.

9 Happle R. Pigmentary patterns associated with human mosaicism: a proposed classification. Eur $₹$ Dermatol 1993; 3:170-4.

10 Graf U, Würgler FE, Katz AJ, et al. Somatic mutation and recombination test in Drosophila melanogaster. Environ Mutagen 1984;6:153-88.

11 Harrison BJ, Carpenter R. Somatic crossing-over in Antirrhinum majus. Heredity 1977;38:169-89.

12 Happle R, Koopman R, Mier PD. Hypothesis: vascular twin naevi and somatic recombination in man. Lancet 1990;335: 376-8.

13 Happle R, Hoffmann R, Restano L, Caputo R, Tadini G. Phacomatosis pigmentokeratotica: a melanocyticepidermal twin nevus syndrome. Am f Med Genet 1996;65: 363-5.

14 German J. Bloom syndrome: a mendelian prototype of somatic mutational disease. Medicine 1993;72:393-406. 